\title{
Differentiating the stress buffering functions of perceived versus received social support
}

\author{
Jian Raymond Rui ${ }^{1,2}$. Jieqiong Guo ${ }^{1}$
}

Accepted: 5 December 2021

(c) The Author(s), under exclusive licence to Springer Science+Business Media, LLC, part of Springer Nature 2021

\begin{abstract}
Drawing upon the stress buffering model of social support, this study investigated how perceived social support (PSS), defined as the amount of support individuals think they can mobilize from their network, and received social support (RSS), defined as the level of support individuals have received, moderated the direct and indirect relationships between COVID-19 news exposure (i.e., stressor) and stress via social trust. An online survey from six major cities in China $(N=636)$ revealed that PSS rather than RSS moderated the direct relationship between COVID-19 news exposure and stress such that this relationship was stronger at a low level of PSS than a high level. Additionally, RSS rather than PSS moderated the relationship between COVID-19 news exposure and social trust such that this relationship was stronger at a low level of RSS than a high level. These findings reveal the differential mechanisms by which PSS and RSS function to buffer against stress.
\end{abstract}

Keywords Stress coping $\cdot$ Perceived social support $\cdot$ Received social support $\cdot$ COVID-19 $\cdot$ Media exposure

Disaster is conceptualized as serious disruptions of the functioning of a community or a society which require additional resources for coping and resilience (Perry, 2018). In addition to financial and physical damages, COVID-19 has been found to cause a series of mental health issues such as posttraumatic stress disorder (Bridgland et al., 2021), anxiety and depression (Choi et al., 2020), and heightened levels of stress (El-Zoghby et al., 2020; Jewell et al., 2020; Szkody et al., 2020). These mental health issues can be caused by direct or indirect exposure to the pandemic such as consumption of COVID-19-related news (Bendau et al., 2021; Bridgland et al., 2021). Coping with COVID-19-related stress requires additional resources such as social support (Grey et al., 2020; Szkody et al., 2020).

The stress buffering model of social support posits that social support can mitigate the stressor-stress relationship such that individuals with limited social support tend to report a higher level of stress than those with more support (Cohen \& Wills, 1985). Two types of social support are

Jian Raymond Rui

ruijian@scut.edu.cn

1 South China University of Technology, 382 Waihuan East Rd, Guangzhou 510006, China

2 Center for Public Health Risk Surveillance and Information Communication in Guangdong Province, Guangzhou, China identified in the extant scholarship: perceived social support (PSS) and received social support (RSS; Helgeson, 1993). While PSS refers to the amount of support individuals think they can mobilize from their network, RSS refers to the level of support individuals have received (Helgeson, 1993). Although research provided empirical evidence showing the differential main effects of PSS and RSS on stress buffering (Grey et al., 2020; Norris \& Kaniasty, 1996; Szkody et al., 2020; Yu et al., 2020; Zhou \& Yao, 2020), whether these two types of social support may moderate the stressor-stress relationship differently needs further investigation.

First, although previous research found that RSS (Etzion, 1984; Rhodes \& Woods, 1995) could moderate the stressorstress relationship such that this relationship was weak when individuals reported a high level of RSS, these studies operationalized RSS as the support that recipients found satisfactory (Etzion, 1984; Rhodes \& Woods, 1995). Given the boomerang effect of RSS on stress buffering (Bolger et al., 2000; Gleason et al., 2003; Lindorff, 2000; Norris \& Kaniasty, 1996; Wethington \& Kessler, 1986; Zhou \& Yao, 2020), it is critical to retest whether RSS moderates the effect of stressor on stress. This study conceptualizes COVID-19 news exposure as the stressor, as research found exposure to news about disasters often enhanced one's level of stress (Busso et al., 2014; Pfefferbaum et al., 2000; Stainback et al., 2020). 
Additionally, prior research shows that exposure to disaster-related news could make individuals underestimate the level of social trust, which then elevates the level of stress (Gross et al., 2004; Moy \& Scheufele, 2000). However, the role that social support plays in this indirect stressor-stress relationship remains understudied. Although empirical evidence showing that social support could moderate the indirect stressor-stress relationship has started to emerge (He et al., 2021), little research has compared the moderation effects of PSS and RSS on this indirect relationship. Investigation on the potential differences in the moderation effects of PSS and RSS on the stressor-stress relationship can provide insights on the mechanism by which these two types of social support may buffer against stress. Hence, another goal of this study is to bridge this gap by investigating whether these two types of social support moderated the indirect relationship between COVID-19 news exposure and stress through social trust.

\section{Stress Buffering Functions of PSS and RSS}

No matter whether social support is perceived (i.e., PSS) or enacted (i.e., RSS, Helgeson, 1993), previous research has provided empirical evidence showing that both types of social support can weaken the effect of stressor on stress (Davidson \& Demaray, 2007; Etzion, 1984; Mitchell et al., 2014; Rhodes \& Woods, 1995; Smith et al., 2013; Wethington \& Kessler, 1986). With specific regard to the stress buffering function of RSS, Rhodes and Woods (1995) found that received cognitive guidance moderated the effect of social strain on depression such that social strain exhibited a weaker effect on depression when individuals reported to receive a high level of social support. Likewise, Etzion (1984) found that among individuals receiving a high level of social support in the workplace, the effect of stress on burnout was weaker compared to those receiving a low level of social support. However, the measure of RSS in both studies addressed the level of satisfaction with received support (Etzion, 1984; Rhodes \& Woods, 1995). Hence, the social support they measured was the level of RSS with which support recipients were satisfied (Etzion, 1984; Rhodes \& Woods, 1995). In other words, both studies suggest that only satisfactory RSS could mitigate the stressor-stress relationship (Etzion, 1984; Rhodes \& Woods, 1995).

Indeed, research suggests that RSS may not always be effective in stress coping (Bolger et al., 2000; Gleason et al., 2003; Lindorff, 2000; Norris \& Kaniasty, 1996; Wethington \& Kessler, 1986; Zhou \& Yao, 2020). Some research did not find that RSS could facilitate stress coping (Norris \& Kaniasty, 1996; Wethington \& Kessler, 1986; Zhou \& Yao, 2020). For example, Zhou and Yao (2020) did not find a significant direct relationship between RSS and acute stress symptoms. Norris and Kaniasty (1996) found that RSS was indirectly related to psychological distress via PSS, but their direct relationship was not significant. Some studies provided empirical evidence showing that RSS could even heighten the level of stress (Bolger et al., 2000; Gleason et al., 2003; Lindorff, 2000). For instance, Lindorff (2000) found that receiving emotional support elevated stress among men, whereas this relationship was not significant among women. This might be because receiving emotional support was an acknowledgement of being weak and challenged masculinity, which was especially critical to men and thereby made them more stressful (Lindorff, 2000). Furthermore, even among those studies which found a negative direct relationship between RSS and stress, some research shows that the mitigating effect of RSS on stress was less strong compared to PSS (Szkody et al., 2020; Yu et al., 2020).

Several explanations are offered to account for these seemingly counterintuitive findings. The first noted the discrepancy between PSS and RSS (Stefanone et al., 2012), which might not help lower the level of stress and could even elevate it. Second, even if individuals have received the support they expect, they may not find it helpful (Krause, 1987). For example, Lehman et al. (1986) found that support recipients reported a range of support attempts that they perceived unhelpful. Additionally, although individuals may be unsatisfied with RSS, they are still expected to return the favor due to the social norm of reciprocation (Uehara, 1995). Therefore, the stress buffering effect of RSS should be contingent upon many situational factors (Barrera, 2000) such as whether recipients are satisfied with the received support. As findings of Etzion (1984) and Rhodes and Woods (1995) suggest that satisfactory RSS mitigated the stressor-stress relationship, it was satisfactory RSS rather than RSS moderated the stressor-stress relationship. In other words, the possible moderation effect of RSS on the stressor-stress relationship might be further moderated by the extent to which support recipients were satisfied with RSS.

Conversely, empirical evidence on the moderation effect of PSS on the stressor-stress relationship is more consistent (Davidson \& Demaray, 2007; Mitchell et al., 2014; Smith et al., 2013; Wethington \& Kessler, 1986). For example, through a longitudinal survey, Smith et al. (2013) found that military social support could lower the impact of stressfulness of training on posttraumatic stress symptomatology of Marines. Likewise, Mitchell et al. (2014) found that PSS moderated the effect of injuries on athletes' psychological distress such that injured athletes perceiving high availability of social support reported lower impacts of injuries on their psychological distress. As PSS indicates the extent to which individuals think support is available when needed (Helgeson, 1993), higher levels of PSS can provide individuals 
with a sense of security and increase their confidence in stress coping (Wethington \& Kessler, 1986). Therefore, PSS may moderate the stressor-stress relationship such that individuals perceiving higher availability of social support may be less affected by the stressor and report lower levels of stress (Cohen \& Wills, 1985; Rueger et al., 2016).

The present study conceptualizes exposure to news about COVID-19 as a type of stressor, given that research consistently found exposure to news about disasters could increase the chance of mental health problems (Busso et al., 2014; He et al., 2021; Pfefferbaum et al., 2000; Stainback et al., 2020). Cultivation theory (Gerbner, 1998) provides a theoretical framework which may explain these results. According to cultivation theory, most people's perception of reality is constructed by media (Gerbner, 1998). By describing a "media world", media shape how people perceive the world such that heavy media users are more likely to perceive the world consistently with what media present (Gerbner, 1998). Despite a wealth of criticisms which argued that cultivation theory did not control other factors that may shape people's perception of the world (Romer et al., 2014), research still provided empirical support to the theory. For instance, as violence is prevalent on American television, heavy viewers in the U.S. tended to view the world more dangerous after other variables were controlled (Riddle et al., 2011; Romer et al., 2003). During the COVID-19 outbreak, people may be exposed to a range of negative news such as death tolls, economic recession, lack of medical resources, and discrimination. These media messages can make people view the world more negatively, for instance, by heightening their estimated levels of threats of COVID-19 (Stainback et al., 2020) or making them feel the future is characterized by more uncertainty (He et al., 2021). Consequently, COVID19 news exposure could be related to an elevated level of stress, which has received empirical support (Bendau et al., 2021; Bridgland et al., 2021). As reviewed earlier, PSS is more likely to mitigate the stressor-stress relationship compared to RSS. Thus, the following hypothesis was proposed.

H1: PSS rather than RSS moderates the relationship between COVID-19 news exposure and stress such that this relationship is weaker at a high level of PSS than a low level.

\section{Stress Buffering of PSS and RSS through Social Trust}

The explanation above suggests that the direct relationship between COVID-19 news exposure and stress may be partially explained by an erosion in social trust, conceptualized as the extent to which individuals trust the general society (Newton \& Zmerli, 2011). Both cross-sectional (Moy
\& Scheufele, 2000) and longitudinal research (Gross et al., 2004) provided empirical evidence showing that exposure to negative news could lower social trust. Moreover, natural disasters could trigger the instinct of self-protection (Miller, 2006; Ritchie \& Gill, 2007). Thus, excessive exposure to news about COVID-19 might make individuals feel insecure, which could make them over-evaluate selfishness of general others and under-evaluate their altruism (Miller, 2006; Ritchie \& Gill, 2007). All these perceptions could lower individuals' appraisal of social trust. As social trust could make individuals less stressed by elevating their sense of security (Abbott \& Freeth, 2008), the relationship between COVID-19 news exposure and stress may be mediated by social trust.

Another goal of this study is to examine whether PSS and RSS moderate the indirect relationship between exposure to news about COVID-19 and stress through social trust. Individuals with more social support may have better views about general others (Liu et al., 2021), which offers them more confidence in stress coping. Although individuals may not always receive the support they find helpful (Lehman et al., 1986), the act of providing support functions as an expression of concern for the support recipients (Semmer et al., 2008). Hence, individuals with a high level of RSS may be less affected by COVID-19 news exposure and report a higher level of social trust compared to those with a low level, which could help their stress coping.

H2: RSS moderates the effect of COVID-19 news exposure on social trust such that its effect is weaker at a high level of RSS compared to a low level. The indirect relationship between COVID-19 news exposure and stress via social trust is moderated by RSS such that their indirect relationship is weaker at a high level of RSS compared to a low level.

Additionally, Norris and Kaniasty (1996) argued that PSS is often a result of RSS because people reporting a high level of PSS should have received a large amount of social support. Thus, individuals with a high level of PSS may dismiss the negative influence of news cultivation because of their perceived availability of coping resources. Hence, the negative effect of news exposure on social trust should be weaker among those with a high level of PSS compared to a low level.

H3: PSS moderates the effect of COVID-19 news exposure on social trust such that its effect is weaker at a high level of PSS compared to a low level. The indirect relationship between COVID-19 news exposure and stress via social trust is moderated by PSS such that their indirect relationship is weaker at a high level of PSS compared to a low level. 
The present study focuses on China for the following considerations. Although preliminary evidence emerged which shows that Chinese reported a lower level of stress than Americans during the peak of COVID-19 (Wang et al., 2021), the way China's government responded to the pandemic might have added to the stress level of Chinese citizens. First, the central government in China issued strict executive orders which placed millions of individuals under quarantine. As quarantine contributed to an increase in mental health issues (Gan et al., 2020), the stress problem of Chinese individuals should not be dismissed. Additionally, despite an escalated level of media censorship in China during the pandemic (Li, 2020), negative news still leaked on the lack of transparency of the government in revealing the truth of the early outbreak and the inability of the government to handle the crisis swiftly and effectively. This negative news, along with media censorship, might have elevated the level of stress of Chinese individuals. Taken together, the unique sociopolitical environment in China suggests that Chinese individuals might have to cope with more stressors and thereby might be in greater need of social support. This provides a unique context for testing the hypotheses proposed in the present study.

\section{Method}

\section{Study Procedure and Sample}

An online survey was launched between March 21 and 28, 2020. The researchers collaborated with Wenjuanxing (a large company that provides sampling services in China) to recruit participants. Participants were adult residents in four largest cities in China (Beijing, Shanghai, Guangzhou, Shenzhen) and two big cities with a large number of COVID-19 cases in late January and February (Wuhan and Hangzhou; Diao et al., 2020). This sample was prescribed because these cities are densely populated and have important domestic and international connections. This can increase the severity of the pandemic, which might elevate the level of stress of residents in these places. A convenience sample was used to recruit participants.

Participants were first exposed to the informed consent form, which presented the goal, procedure, benefits and risks of completing the survey. They were offered the option to proceed to or quit the survey at the end of the page where the informed consent form was shown. The survey started with a description of how COVID-19 broke out and developed in China in late 2019 and early 2020. This specific timing was selected because it was the time when the number of COVID-19 cases in China grew rapidly every day (Worldometers, 2020). Participants were then asked to recall their experiences with other people and how they felt during that time, followed by questions measuring their level of stress, social trust, PSS, RSS, and demographic information. The research ethics committee at the university approved this procedure (21006).

All participants completed the survey, leading to a final sample of 636 responses. While there were 105 participants from Beijing and 107 from Hangzhou, 106 responses were collected from every other city. There were more female participants $(57.9 \%)$ than males, with an average age of almost $30(M=29.79, S D=7.21)$. Nearly two thirds of the participants $(66.5 \%)$ received a bachelor's degree, followed by high school (17.1\%), graduate degree $(8.5 \%)$, middle school (7.1\%) and elementary school (.8\%). Less than half of the participants reported their monthly household income of 12,501-38,500 RMB (1890.82-5823.27 USD, $46.2 \%)$, followed by 8001-12,500 RMB (1210.18-1890.67 USD, 22.8\%), 5001-8000 RMB (756.42-1210.03 USD, 12.16\%), 3501-5000 RMB (527.95-756.27 USD, 6.9\%), 38,501-83,500 RMB (5823.43-12,629.70 USD, 6.4\%), 3500 or below (527.8 USD, $2.5 \%$ ), and 83,501 or above $(12,629.85$ USD, $2.5 \%)$.

\section{Measures}

Stress was assessed through a six-item Likert scale, which was adapted from Cohen et al. (1983), a 5-point Likert scale measuring perceived stress $(0=$ never, $1=$ almost never, $2=$ sometimes, $3=$ fairly often, $4=$ very often). The original scale did not receive good reliability scores probably because it was not validated in China. The researchers thus selected items with high factor loadings and conducted confirmatory factor analysis through the Lavaan package in $\mathrm{R}$ 6.6. The final six questions in the scale $(M=2.39, S D=.73)$ demonstrated satisfactory results of reliability (Cronbach's $\alpha=.80)$ and construct validity $\left(\chi^{2}(9)=17.67, p<.05\right.$, $\mathrm{CFI}=.99, \mathrm{TLI}=.98, \mathrm{RMSEA}=.04, \mathrm{SRMR}=.02$ ).

Social trust was measured based on the 8-item Likert scale by Sturgis et al. (2010), which asked participants to indicate how much they trust general others on a $0-10$ Likert scale. Sturgis et al. (2010) suggested that scholars select items based on their research context. Six items were selected and several of them were reverse coded so that a large number indicates high levels of social trust (Cronbach's $\alpha=.82 ; M=4.80, S D=1.11)$. Table 1 presents the questions measuring stress and social trust.

The received support scale by Wethington and Kessler (1986) was adapted to measure RSS (Cronbach's $\alpha=.84$; $M=4.90, S D=1.11)$. Participants were asked to recall in late January and February whether someone would listen to them, cheer or comfort them, referred to some other helper, provided a new way of seeing the problem, gave them advice, provided them with medical supplies, and offered food or other supplies to them $(1=$ strongly disagree, 
Table 1 The scales of stress and social trust

In late January and February when the number of COVID-19 cases grew rapidly every day, how often....

Stress (0-4)

1. Were you upset because of something that happened unexpectedly?

2. Did you feel that you were unable to control the important things in your life

3. Did you feel nervous and stressed?

4. Did you feel not confident about your ability to handle your personal problems?

5. Were you unable to control irritations in your life?

6. Did you feel difficulties were piling up so high that you could not overcome them?

Social Trust (0-10)

1. I tended to be cynical and skeptical of others' intentions (reverse coding).

2. I believed that most people would take advantage of you if you let them (reverse coding).

3. I thought that most of the people I dealt with were honest and trustworthy.

4. I was suspicious when someone did something nice for me (reverse coding).

5. My first reaction was to trust people.

6. I had a good deal of faith in human nature.

$7=$ strongly agree). The last two items were added to match the need of Chinese individuals in quarantine.

The scale on perceived availability of social support by Sherbourne and Stewart (1991) was adapted to measure PSS (Cronbach's $\alpha=.93 ; M=5.42, S D=.92$ ). The final scale included 16 items measuring participants' perceptions of availability of social support on a 7-point Likert scale (e.g., "someone could be counted on to listen to me when I need to talk").

Exposure to news about COVID-19 was measured by asking participants to recall how often they were exposed to news about the pandemic every day in late January and February ( $1=$ never, $2=$ almost never, $3=$ a little, $4=$ less than half of the news to which I was exposed every day, $5=$ half of the news to which I was exposed every day, $6=$ more than half of the news to which I was exposed every day, $7=$ almost all, $8=$ all). Several examples of COVID-19 news were listed, including the number of cases, death tolls, excessive workload of health professionals, insufficient medical supplies, the inability of government officials and organizations to provide timely help. Participants' response ranged from 1 to $7(M=4.39$, $S D=1.29$ ). Table 2 presents descriptive results of and bivariate correlations between variables mentioned above.

\section{Statistical Analysis}

As PSS and RSS were proposed to moderate the direct and indirect relationship between COVID-19 news exposure and stress via social trust, hypotheses of the current study are essentially moderated mediation. Therefore, Hayes' Macro Process 3.4, which provides a convenient method to test moderated mediations, was used to test hypotheses. Specifically, model 8 in Hayes' Macro Process 3.4 was chosen because it matches the hypotheses (Hayes, 2017). Thus, PSS and RSS were entered in the model separately as the moderator to test the proposed moderated mediation hypotheses, after biological sex, age, education, monthly household income, and city of residence which was dummy coded five times were controlled. Notably, Macro Process provides $\mathrm{R}^{2}$ instead of adjusted $\mathrm{R}^{2}$ and unstandardized coefficients instead of standardized coefficients (Hayes, 2017). 95\% confidence interval (CI) was reported to indicate the significance of the proposed moderation and moderated mediation relationships. If zero is not included in the $95 \% \mathrm{CI}$, the tested relationship is significant.
Table 2 Descriptive statistics and zero-order correlations; means (standard deviations) presented along the diagonal

\begin{tabular}{llllll}
\hline & $\begin{array}{l}\text { COVID-19 news } \\
\text { exposure }\end{array}$ & Social trust & Stress & RSS & PSS \\
\hline $\begin{array}{l}\text { COVID-19 news } \\
\text { exposure }\end{array}$ & $4.39(1.29)$ & $-.27 * * *$ & $.24 * * *$ & -.05 & $-.11^{* * *}$ \\
Social trust & & $4.80(1.11)$ & $-.39 * * *$ & $.34 * * *$ & $.44^{* * *}$ \\
Stress & & $2.39(.73)$ & -.05 & $-.14 * * *$ \\
RSS & & & $4.90(1.11)$ & $.71^{* * *}$ \\
PSS & & & & $5.42(.92)$ \\
\hline$* * * p<.001, * * p<.01$ & & & &
\end{tabular}




\section{Results}

COVID-19 news exposure, PSS, their interaction, and all control variables explained $25.86 \%$ of total variances in social trust $\left(\mathrm{R}^{2}=.2586, F(12,623)=18.11, p<.001\right)$. Although COVID-19 news exposure $(\mathrm{B}=-.20, p<.001$, Table 3$)$ and PSS $(\mathrm{B}=.52, p<.001)$ both predicted social trust significantly, their interaction effect was not significant

Table 3 The mediation model regressing stress on COVID-19 news exposure through social trust moderated by PSS

\begin{tabular}{lll}
\hline & Social trust & Stress \\
\hline Sex & $\mathrm{B}$ & $\mathrm{B}$ \\
Age & -.11 & .03 \\
Education & .00 & -.00 \\
Income & .00 & .01 \\
City (Wuhan) & .01 & -.03 \\
City (Beijing) & .15 & -.01 \\
City (Shanghai) & .08 & .08 \\
City (Guangzhou) & -.06 & .09 \\
City (Shenzhen) & -.06 & -.06 \\
COVID-19 news exposure & -.22 & .11 \\
PSS & $-.20^{* * *}$ & $.08^{* * *}$ \\
Exposure $*$ PSS & $.52^{* * *}$ & .05 \\
Social trust & .01 & $-.05^{*}$ \\
$\mathrm{R}^{2}, \mathrm{~F}$ & $\mathrm{NA}$ & $-.24^{* * *}$ \\
& $.26 * * *, F(12$, & $.20^{* * *}, F(13$, \\
& $623)=18.11$ & $622)=11.61$ \\
\hline
\end{tabular}

$* * * p<.001, * p<.05$

Fig. 1 RSS moderated the effect of COVID-19 news exposure on social trust $(p=.78) . \mathrm{H} 3$ was rejected. The mediation between COVID19 news exposure and stress through social trust moderated by PSS was not significant $(-.002,95 \%$ CI: $[-.02, .01])$.

However, PSS moderated the relationship between COVID-19 news exposure and stress $(\mathrm{B}=-.05, p<.02)$ such that this relationship was only significant at a low level of PSS ( $\mathrm{B}=.12, p<.001$, Fig. 1). Additionally, exposure predicted stress positively $(\mathrm{B}=.08, p<.001)$ whereas social trust lowered stress $(\mathrm{B}=-.24, p<.001)$. PSS was not related to stress $(p=.17)$. H1 was supported.

In addition, COVID-19 news exposure, RSS, their interaction, and all control variables explained $20.38 \%$ of total variances in social trust $\left(\mathrm{R}^{2}=.2038, F(12,623)=13.29\right.$, $p<.001)$. RSS moderated the relationship between exposure and social trust $(\mathrm{B}=.07, p<.01$, Table 4$)$ such that their relationship was stronger at a low level of RSS $(\mathrm{B}=-.29$, $p<.001$, Fig. 2) compared to a high level $(\mathrm{B}=-.14$, $p<.01)$. Moreover, exposure predicted social trust negatively $(\mathrm{B}=-.22, p<.001)$ whereas RSS elevated social trust $(\mathrm{B}=.34, p<.001)$. Furthermore, the moderated mediation was significant $(-.02,95 \%$ CI: $[-.03,-.003])$. Specifically, the indirect relationship between COVID-19 news exposure and stress via social trust was stronger at a high level of RSS $(.07,95 \%$ CI: $[.05, .10])$ compared to a low level $(.04,95 \%$ CI: $[.01, .06]) . \mathrm{H} 2$ was supported.

However, RSS did not moderate the relationship between COVID-19 news exposure and stress $(p=.36$, Table 4$)$. This lends further support to $\mathrm{H} 1$. Exposure $(\mathrm{B}=.08, p<.001)$ and social trust $(\mathrm{B}=-.25, p<.001)$ predicted stress significantly. Notably, RSS was positively related to stress $(\mathrm{B}=.06$, $p<.03)$.

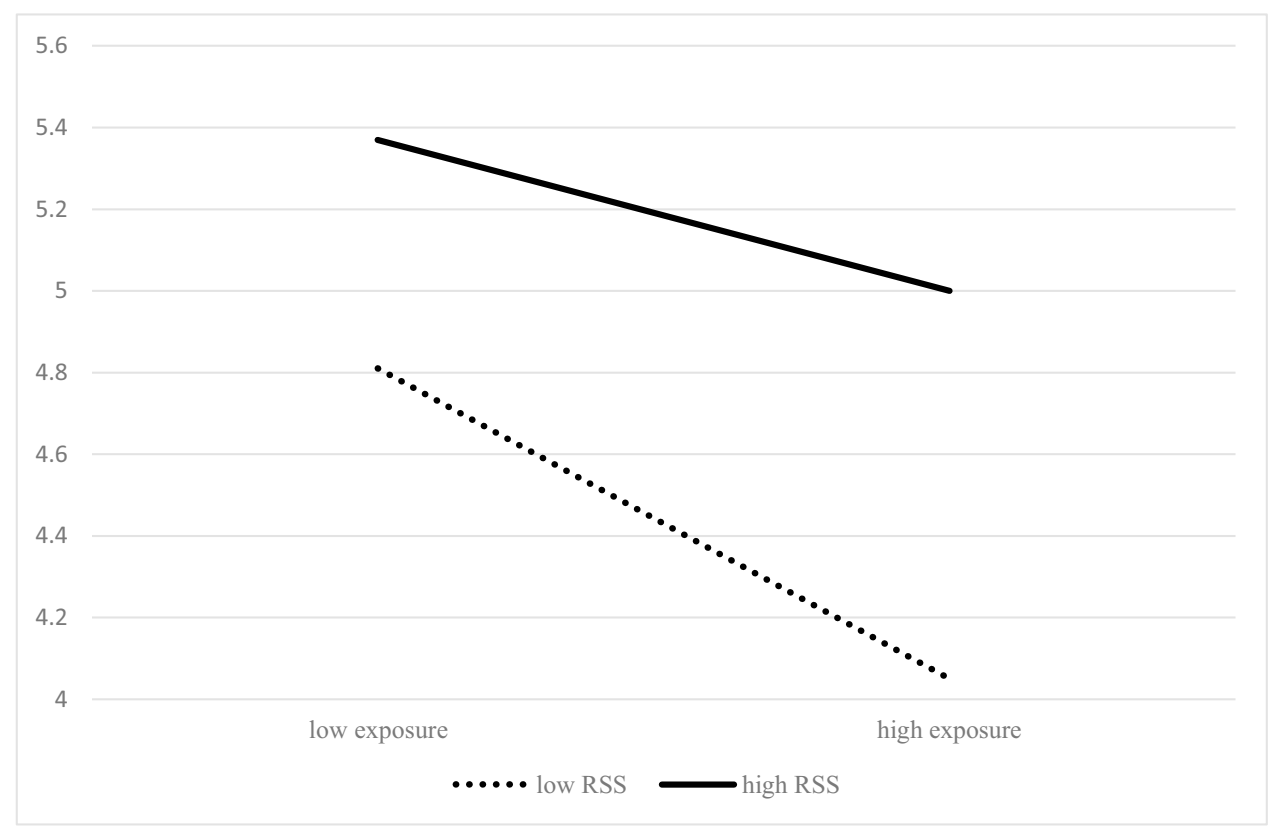


Table 4 The mediation model regressing stress on COVID-19 news exposure through social trust moderated by RSS

\begin{tabular}{lll}
\hline & Social trust & Stress \\
\hline & $\mathrm{B}$ & $\mathrm{B}$ \\
Sex & -.09 & .03 \\
Age & .01 & -.00 \\
Education & .00 & .01 \\
Income & .04 & -.03 \\
City (Wuhan) & -.00 & -.01 \\
City (Beijing) & .13 & .08 \\
City (Shanghai) & -.05 & .08 \\
City (Guangzhou) & -.06 & -.07 \\
City (Shenzhen) & -.14 & .11 \\
COVID-19 news exposure & $-.22 * * *$ & $.08^{* * *}$ \\
RSS & $.34 * * *$ & $.06 *$ \\
Exposure $*$ RSS & $.07 * *$ & -.02 \\
Social trust & $\mathrm{NA}$ & $-.25^{* * *}$ \\
$\mathrm{R}^{2}, \mathrm{~F}$ & $.20^{* * *}, F(12$, & $.19^{* * *}, F(13$, \\
& $623)=13.29$ & $622)=11.50$ \\
\hline
\end{tabular}

$* * * p<.001, * p<.05$

\section{Discussion}

Although disasters like COVID-19 usually make people stressed, individuals often exchange social support as a coping strategy. The present study examined whether RSS and PSS moderated the direct and indirect relationship between COVID-19 news exposure and stress through social trust. Findings reveal that PSS rather than RSS moderated the direct relationship between COVID-19 news exposure and stress. However, RSS moderated the relationship between COVID-19 news exposure and social trust such that RSS enhanced this relationship. Therefore, the indirect relationship between COVID-19 news exposure and stress via social trust was stronger for those that have received a high level of social support. Conversely, PSS did not moderate the relationship between COVID-19 news exposure and social trust. These findings extend the current scholarship on social support by demonstrating the differential functions of these two types of social support in stress buffering.

First, PSS moderated the direct relationship between COVID-19 news exposure and stress. Consistent with prior research which revealed that PSS moderated the stressorstress relationship (Davidson \& Demaray, 2007; Mitchell et al., 2014; Smith et al., 2013; Wethington \& Kessler, 1986), these findings provide additional evidence showing that the stressor-stress relationship is weaker when individuals report a high level of PSS than a low level. PSS indicates one's appraisal of the availability of support (Norris \& Kaniasty, 1996). Thus, people reporting a high level of PSS likely think they can mobilize sufficient resources when needed. This gives them additional confidence in coping with stress (Wethington \& Kessler, 1986), which may dampen the effect of COVID-19 news exposure on stress.

Notably, not all studies found a significant moderation effect of PSS on the stressor-stress relationship (Burton et al., 2004). However, a meta-analysis study provides empirical support to the moderation effect of PSS on the
Fig. 2 PSS moderated the relationship between COVID-19 exposure and stress

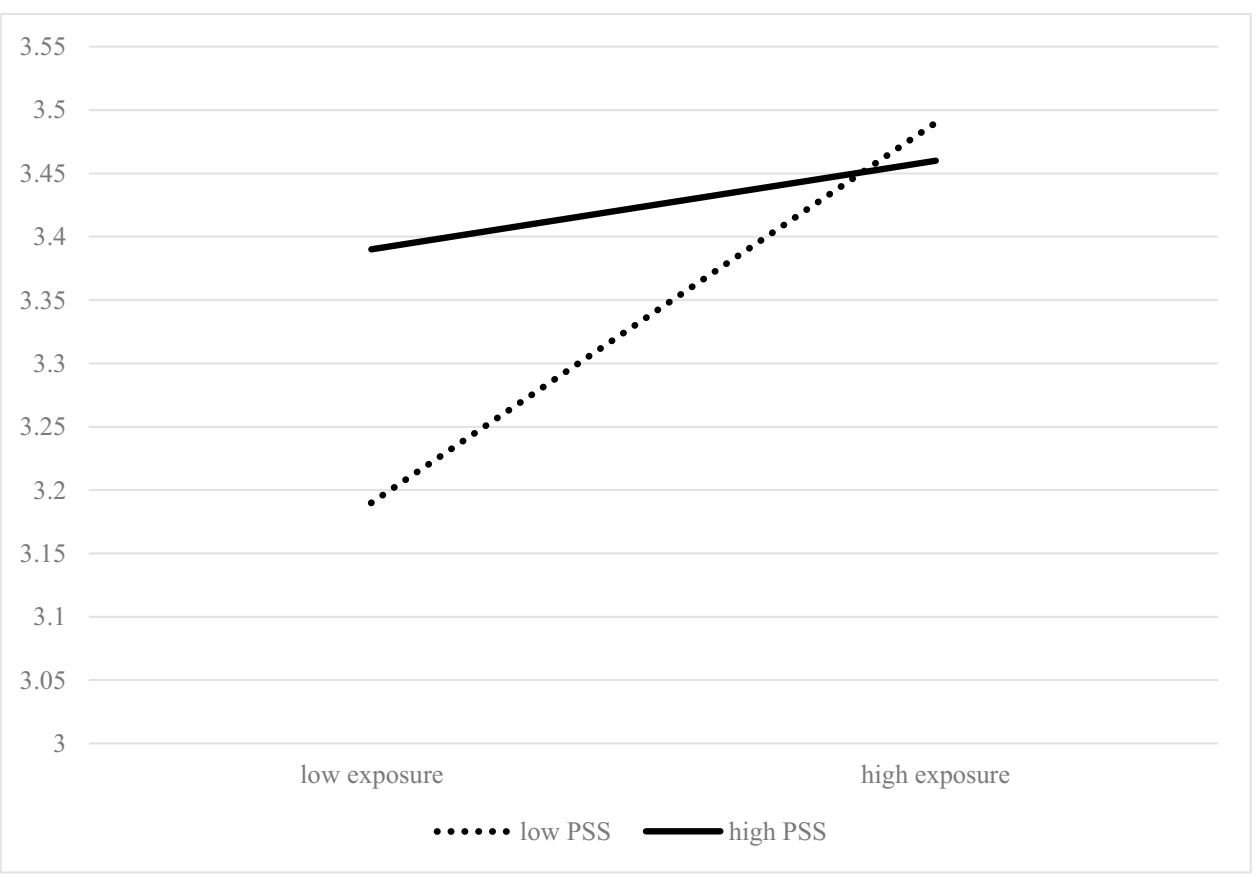


stressor-stress relationship (Rueger et al., 2016). This suggests that the reason why Burton et al. (2004) did not find a significant moderation effect of PSS may be related to the study. Specifically, the type of stressor that Burton et al. (2004) focused on was major life events. This type of stressor is more significant than news exposure. Therefore, coping with major life events requires more resources. Hence, variables such as locus of control, self-efficacy, and personal resources should be more likely to moderate the effect of major life events on stress.

By contrast, the present study did not find evidence demonstrating that RSS could moderate the relationship between COVID-19 news exposure and stress. This result challenges prior research which found that RSS moderated the stressorstress relationship (Etzion, 1984; Rhodes \& Woods, 1995) and suggests that the significant moderation effect in those studies was perhaps found because they focused on satisfactory RSS. In other words, the level of satisfaction with RSS in those studies (Etzion, 1984; Rhodes \& Woods, 1995) might moderate the moderation effect of RSS on the stressor-stress relationship. Hence, the present study not only provides additional evidence which demonstrates that RSS may not always be effective in stress coping (Bolger et al., 2000; Gleason et al., 2003; Lindorff, 2000; Norris \& Kaniasty, 1996; Wethington \& Kessler, 1986; Zhou \& Yao, 2020), but also lends support to Barrera (2000), which posited that the stress buffering effect of RSS depends on many situational factors.

In addition, the present investigation develops the scholarship on the stress buffering function of social support by distinguishing how PSS and RSS moderated the indirect relationship between COVID-19 news exposure and stress through social trust. The current research did not find that PSS moderated the relationship between COVID-19 news exposure and social trust. This can be explained by the discrepancy between PSS and RSS (Stefanone et al., 2012). Even if people report a high level of PSS, they might be aware that they may not be able to mobilize all the resources when needed. This awareness may not help boost their evaluation of altruism of general others. Consequently, the relationship between COVID-19 news exposure and social trust was similar at a high versus low level of PSS. Taken together, PSS facilitates stress coping by dampening the direct effect of stressor.

Conversely, RSS moderated the indirect relationship between COVID-19 news exposure and stress through social trust such that this indirect relationship was stronger at a low level of RSS compared to a high level. One possible explanation is that the act of social support provision is an expression of concern for recipients (Semmer et al., 2008). Thus, no matter whether recipients are satisfied with RSS, as long as they have received support, they may feel that other people are altruistic, which might weaken the negative effect of COVID-19 news exposure on social trust. Thus, this finding suggests that the stress buffering function of RSS may be indirect by first dampening the effect of stressor on social trust which then lowers stress level.

It is important to note that previous research found that RSS was indirectly related to stress. For instance, Norris and Kaniasty (1996) found that RSS predicted PSS which then mitigated distress because only when people receive social support can they be confident in the availability of these resources when needed. Similarly, Zhou and Yao (2020) found that the relationship between RSS and acute stress symptoms was fully mediated by needs for relatedness and autonomy. This finding aligns with these studies and suggests that the stress buffering effect of RSS may be indirect. Furthermore, the current result extends these studies by suggesting a moderated mediation. Therefore, RSS may not only exhibit a main effect on the mediator which can lower the level of stress (Norris \& Kaniasty, 1996; Zhou \& Yao, 2020) but also weaken the effect of stressor on the mediator.

In addition to theoretical implications above, this study highlights the importance of social support exchanges to stress coping during disasters. Although quarantines reduce the chance of social interactions, mediated communication through Internet-based technologies may compensate for this limitation. Online, individuals may maintain interactions with existing offline contacts, and these relationshipmaintenance conversations can make them feel that they can mobilize social support from their network when needed, thereby potentially heightening their level of PSS. In addition, it is recommended to exchange RSS with online connections that individuals do not necessarily know or meet frequently, as this can improve their overall evaluation of society and enhance their level of social trust. Specifically, although the geographic distance limits one's ability to exchange instrumental support, individuals can exchange low-cost support such as informational and emotional support with online contacts. This makes reciprocating social support easier and could potentially mitigate the contribution of RSS to an increased level of stress.

\section{Limitations and Future Directions}

Findings of the current study must be interpreted with following caveats. First, although the relationship between media exposure, stress, and social trust is not the focus of the present study, the cross-sectional nature of this study makes it impossible to build causal relationships. Future research can conduct longitudinal investigations to understand the complex relationship between media exposure, stress, and social trust.

Second, this study was conducted between March 21 and 282,020 , when there was a wealth of negative news, rumors, and misinformation on media. This timing might account 
for the decreased level of social trust and the heightened level of stress.

Additionally, the current study used a convenience sample limited to residents in six major cities in China. Compared to the national population, the current sample is better educated and richer. This limits the generalizability of current results to less developed cities and rural areas.

Finally, this study was conducted in China. As mentioned earlier, the unique sociopolitical environment in China may explain additional variances in stress and limit the generalizability of current findings. Cross-cultural comparisons are needed.

\section{Conclusion}

The present study investigated how PSS and RSS affected Chinese individuals' level of stress during the COVID-19 outbreak. Findings extend the stress buffering model of social support by illustrating how these two types of social support may facilitate stress coping. While RSS could improve one's appraisal of general others which indirectly helped stress coping, PSS directly dampened media effects on stress. Thus, even if disasters may limit the chance of communication, it is still important to encourage individuals to exchange social support so that a sense of community can be built and maintained.

Data Availability The data of the current study is available through https://doi.org/10.6084/m9.figshare.14823408. Other materials of the study can be accessed via https://doi.org/10.6084/m9.figshare.14823 417.

Code Availability Data analysis was conducted via SPSS 23.

\section{Declarations}

Conflict of Interest The present study involves no conflicts of interest.

Ethics Approval The present study received approval from the research ethics committee at South China University of Technology.

Consent to Participate The informed consent form was presented to participants online prior to the survey. They indicated their agreement to participate by clicking the "agree" button to proceed to the survey.

Consent for Publication The author gives the publisher the permission to publish the work

\section{References}

Abbott, S., \& Freeth, D. (2008). Social capital and health: Starting to make sense of the role of generalized trust and reciprocity. Journal of Health Psychology, 13(7), 874-883. https://doi.org/ $10.1177 / 1359105308095060$
Barrera, M. (2000). Social support research in community psychology. In J. Rappaport, \& E. Seidman (Eds.), Handbook of community psychology (pp. 215-245). Kluwer Academic/Plenum Publishers.

Bendau, A., Petzold, M. B., Pyrkosch, L., Maricic, L. M., Betzler, F., Rogoll, J., et al. (2021). Associations between COVID-19 related media consumption and symptoms of anxiety, depression and COVID-19 related fear in the general population in Germany. European Archives of Psychiatry and Clinical Neuroscience, 271(2), 283-291. https://doi.org/10.1007/s00406-020-01171-6

Bolger, N., Zuckerman, A., \& Kessler, R. C. (2000). Invisible support and adjustment to stress. Journal of Personality and Social Psychology, 79(6), 953-961. https://doi.org/10.1037/0022-3514. 79.6.953

Bridgland, V. M., Moeck, E. K., Green, D. M., Swain, T. L., Nayda, D. M., Matson, L. A., et al. (2021). Why the COVID-19 pandemic is a traumatic stressor. PLoS One, 16(1), e0240146. https://doi.org/ 10.1371/journal.pone.0240146

Burton, E., Stice, E., \& Seeley, J. R. (2004). A prospective test of the stress-buffering model of depression in adolescent girls: No support once again. Journal of Consulting and Clinical Psychology, 72(4), 689-697. https://doi.org/10.1037/0022-006x.72.4.689

Busso, D., McLaughlin, K. A., \& Sheridan, M. A. (2014). Media exposure and sympathetic nervous system reactivity predict PTSD symptoms after the Boston Marathon bombings. Depression Anxiety, 31(7), 551-558. https://doi.org/10.1002/da.22282

Choi, E. P. H., Hui, B. P. H., \& Wan, E. Y. F. (2020). Depression and anxiety in Hong Kong during COVID-19. International Journal of Environmental Research and Public Health, 17(10), 3740. https:// doi.org/10.3390/ijerph17103740

Cohen, S., \& Wills, T. A. (1985). Stress, social support, and the buffering hypothesis. Psychological Bulletin, 98(2), 310-357. https:// doi.org/10.1037/0033-2909.98.2.310

Cohen, S., Kamarck, T., \& Mermelstein, R. (1983). A global measure of perceived stress. Journal of Health and Social Behavior, 24(4), 385-396. https://doi.org/10.2307/2136404

Davidson, L. M., \& Demaray, M. K. (2007). Social support as a moderator between victimization and internalizing-externalizing distress from bullying. School Psychology Review, 36(3), 383-405. https://doi.org/10.1080/02796015.2007.12087930

Diao, M., Zhang, S., Chen, D., \& Hu, W. (2020). The novel coronavirus (COVID-19) infection in Hangzhou: An experience to share. Infection Control \& Hospital Epidemiology, 41(7), 874-875. https://doi.org/10.1017/ice.2020.62

El-Zoghby, S. M., Soltan, E. M., \& Salama, H. M. (2020). Impact of the COVID-19 pandemic on mental health and social support among adult Egyptians. Journal of Community Health, 45(4), 689-695. https://doi.org/10.1007/s10900-020-00853-5

Etzion, D. (1984). Moderating effect of social support on the stressburnout relationship. Journal of Applied Psychology, 69(4), 615622. https://doi.org/10.1037/0021-9010.69.4.615

Gan, Y., Ma, J., Wu, J., Chen, Y., Zhu, H., \& Hall, B.J. (2020). Immediate and delayed psychological effects of providence-wide lockdown and personal quarantine during the COVID-19 outbreak in China. Psychological Medicine, 1-12. https://doi.org/10.1017/ s0033291720003116.

Gleason, M. E. J., Iida, M., Bolger, N., \& Shrout, P. E. (2003). Daily supportive equity in close relationships. Personality and Social Psychology Bulletin, 29(8), 1036-1045. https://doi.org/10.1177/ 0146167203253473

Grey, I., Arora, T., Thomas, J., Saneh, A., Tohme, P., \& Abi-Habib, R. (2020). The role of perceived social support on depression and sleep during the COVID-19 pandemic. Psychiatry Research, 293, 113452. https://doi.org/10.1016/j.psychres.2020.113452

Gross, K., Aday, S., \& Brewer, P. R. (2004). A panel study of media effects on political and social trust after September 11, 2001. 
The Harvard International Journal of Press/Politics, 9(4), 49-73. https://doi.org/10.1177/1081180x04269138

Hayes, A. (2017). Introduction to mediation, moderation, and conditional process analysis: A regression-based approach (the second edition). Guilford Press.

He, X., Zhang, Y., Chen, M., Zhang, J., Zou, W., \& Luo, Y. (2021). A moderated mediation model of intolerance of uncertainty and perceived social support. Frontiers in Psychiatry, 11. https:// doi.org/10.3389/fpsyg.2020.613368

Helgeson, V. S. (1993). Two important distinctions in social support: Kind of support and perceived versus received. Journal of Applied Social Psychology, 23(10), 825-845. https://doi.org/ 10.1111/j.1559-1816.1993.tb01008.x

Jewell, J. S., Farewell, C. V., Welton-Mitchell, C., Lee-Winn, A., Walls, J., \& Leiferman, J. A. (2020). Mental health during the COVID-19 pandemic in the United States: Online survey. JMIR Formative Research, 4(10), e22043. https://doi.org/10.2196/ preprints. 22043

Krause, N. (1987). Satisfaction with social support and self-rated health in older adults. The Gerontologist, 27(3), 301-308. https://doi.org/ 10.1093/geront/27.3.301

Lehman, D. R., Ellard, J. H., \& Wortman, C. B. (1986). Social support for the bereaved: Recipients' and providers' perspectives on what is helpful. Journal of Consulting and Clinical Psychology, 54(4), 438-446. https://doi.org/10.1037/0022-006x.54.4.438

$\mathrm{Li}, \mathrm{J}$. (2020). China is dispatching journalists to tell the coronavirus story it wants its people to hear. Quartz. https://qz.com/17980 70/china-seeks-to-create-positive-media-coverage-about-coron avirus/

Lindorff, M. (2000). Is it better to perceive than receive? Social support, stress and strain for managers. Psychology, Health \& Medicine, 5(3), 271-286. https://doi.org/10.1080/713690199

Liu, X., Xiang, G., \& Zhang, L. (2021). Social support and social commerce purchase intention: The mediating role of social trust. Social Behavior and Personality, 49(7), 1-7. https://doi.org/10. 2224/sbp.10381

Miller, D. S. (2006). Visualizing the corrosive community: Looting in the aftermath of hurricane Katrina. Space and Culture, 9(1), 71-73. https://doi.org/10.1177/1206331205283762

Mitchell, I., Evans, L., Rees, T., \& Hardy, L. (2014). Stressors, social support and the buffering hypothesis: Effects on psychological responses of injured athletes. British Journal of Health Psychology, 19(3), 486-508. https://doi.org/10.1111/bjhp.12046

Moy, P., \& Scheufele, D. A. (2000). Media effects on political and social trust. Journalism and Mass Communication Quarterly, 77(4), 744-759.

Newton, K., \& Zmerli, S. (2011). Three forms of trust and their association. European Political Science Review, 3(2), 169-200. https:// doi.org/10.1017/s1755773910000330

Norris, F. H., \& Kaniasty, K. (1996). Received and perceived social support in times of stress: A test of the social support deterioration deterrence model. Journal of Personality and Social Psychology, 71(3), 498-511. https://doi.org/10.1037/0022-3514.71.3.498

Perry, R.W. (2018). Defining disaster: An evolving concept. In E. Quarantelli, R.R. Dynes, \& H. RodrÍguez (Eds.), Handbook of disaster research (pp. 3-22). Springer. doi: https://doi.org/10.1007/ 978-3-319-63254-4_1.

Pfefferbaum, B., Seale, T.W., McDonald, N.B., Brandt, E.N., Rainwater, S.M., Maynard, B.T., Meierhoefer, B., \& Miller, P.D. (2000). Posttraumatic stress two years after the Oklahoma City Bombing in youths geographically distant from the explosion. Psychiatry, 63(4), 358-370. https://doi.org/10.1080/00332747.2000.11024 929

Rhodes, J. E., \& Woods, M. (1995). Comfort and conflict in the relationships of pregnant, minority adolescents: Social support as a moderator of social strain. Journal of Community Psychology,
23(1), 74-84. https://doi.org/10.1002/1520-6629(199501)23:1< 74::aid-jcop2290230107>3.0.co;2-d

Riddle, K., Potter, W. J., Metzger, M. J., Nabi, R. L., \& Linz, D. G. (2011). Beyond cultivation: Exploring the effects of frequency, recency, and vivid autobiographical memories for violent media. Media Psychology, 14(2), 168-191. https://doi.org/10.1080/15213 269.2011.573464

Ritchie, L. A., \& Gill, D. A. (2007). Social capital theory as an integrating theoretical framework in technological disaster research. Sociological Spectrum, 27(1), 103-129. https://doi.org/10.1080/ 02732170601001037

Romer, D., Jamieson, K. H., \& Aday, S. (2003). Television news and the cultivation of fear of crime. Journal of Communication, 53(1), 88-104. https://doi.org/10.1111/j.1460-2466.2003.tb03007.x

Romer, D., Jamieson, P., Bleakley, A., \& Jamieson, K. H. (2014). Cultivation theory: Its history, current status, and future directions. In R. S. Fortner \& P. M. Fackler (Eds.), The handbook of media and mass communication theory (pp. 115-136). John Wiley \& Sons.

Rueger, S. Y., Malecki, C. K., Pyun, Y., Aycock, C., \& Coyle, S. (2016). A meta-analytic review of the association between perceived social support and depression in childhood and adolescence. Psychological Bulletin, 142(10), 1017-1067. https://doi. org/10.1037/bul0000058

Semmer, N. K., Elfering, A., Jacobshagen, N., Perrot, T., Beehr, T. A., \& Boos, N. (2008). The emotional meaning of instrumental social support. International Journal of Stress Management, 15(3), 235 251. https://doi.org/10.1037/1072-5245.15.3.235

Sherbourne, C. D., \& Stewart, A. L. (1991). The MOS social support survey. Social Science and Medicine, 32(6), 705-714. https://doi. org/10.1016/0277-9536(91)90150-b

Smith, B. N., Vaughn, R. A., Vogt, D., King, D. W., King, L. A., \& Shipherd, J. C. (2013). Main and interactive effects of social support in predicting mental health symptoms in men and women following military stressor exposure. Anxiety, Stress, \& Coping, 26(1), 52-69. https://doi.org/10.1080/10615806.2011.634001

Stainback, K., Hearne, B. N., \& Trieu, M. M. (2020). COVID-19 and the 24/7 news cycle: Does COVID-19 news exposure affect mental health? Socius: Sociological Research for a Dynamic World, 6 , 1-15. https://doi.org/10.1177/2378023120969339

Stefanone, M. A., Kwon, K. H., \& Lackaff, D. (2012). Exploring the relationship between perceptions of social capital and enacted support online. Journal of Computer-Mediated Communication, 17(4), 451-466. https://doi.org/10.1111/j.1083-6101.2012. 01585.x

Sturgis, P., Read, S., Hatemi, P., Zhu, G., Trull, T., Wright, M., \& Martin, N. (2010). A genetic basis for social trust? Political Behavior, 32(2), 205-230. https://doi.org/10.1007/s11109-009-9101-5

Szkody, E., Stearns, M., Stanhope, L., \& McKinney, C. (2020). Stressbuffering role of social support during COVID-19. Advance online publication at Family Process. https://doi.org/10.1111/ famp. 12618.

Uehara, E. S. (1995). Reciprocity reconsidered: Gouldner's 'moral norm of reciprocity' and social support. Journal of Social and Personal Relationships, 12(4), 483-502. https://doi.org/10.1177/ 0265407595124001

Wang, C., Tripp, C., Sears, S., Xu, L., Tan, Y., Zhou, D., \& ...Ho, R. (2021). The impact of the COVID-19 pandemic on physical and mental health in the two largest economies in the world: A comparison between the United States and China. Journal of Behavioral Medicine. https://doi.org/10.1007/s10865-021-00237-7

Wethington, E., \& Kessler, R. C. (1986). Perceived support, received support, and adjustment to stressful life events. Journal of Health and Social Behavior, 27(1), 78-89. https://doi.org/10.2307/21365 04

Worldometers (2020). Daily New Cases in China. https://www.world ometers.info/coronavirus/country/china/ 
Yu, H., Li, M., Li, Z., Xiang, W., Yuan, Y., Liu, Y., et al. (2020). Coping style, social support, and psychological distress in the general Chinese population in the early stages of the COVID19 epidemic. BMC Psychiatry, 20, 426. https://doi.org/10.1186/ s12888-020-02826-3

Zhou, X., \& Yao, B. (2020). Social support and acute stress symptoms (ASSs) during the COVID-19 outbreak: Deciphering the roles of psychological needs and sense of control. European Journal of Psychotraumatology, 11(1), 1779494. https://doi.org/10.1080/ 20008198.2020.1779494

Publisher's Note Springer Nature remains neutral with regard to jurisdictional claims in published maps and institutional affiliations. 